\title{
Correction of Hypokalemia Corrects the Abnormalities in Erythrocyte Sodium Transport in Bartter's Syndrome
}

Jeffrey M. Korff, Arthur W. Siebens, and John R. Gill, Jr. Hypertension-Endocrine Branch, and Laboratory of Kidney and Electrolyte Metabolism, National Heart, Lung and Blood Institute, National Institutes of Health, Bethesda, Maryland 20205

A renal tubular transport has been postulated to be a manifestation of a more generalized membrane abnormality. To explore this possibility, sodium concentration, ouabain-sensitive (pump transport), ouabain-resistant but furosemide-sensitive (Na-K-Cl cotransport), and ouabain- and furosemide-resistant (passive transport) ${ }^{22} \mathrm{Na}$ effluxes were measured in erythrocytes obtained from nine patients with Bartter's syndrome before and during correction of hypokalemia. Intracellular $\left[\mathrm{Na}^{+}\right]$in erythrocytes obtained from nine patients with Bartter's syndrome was significantly $(P<0.001)$ higher than that in 30 normal controls $(11.8 \pm 1.8$ vs. $7.3 \pm 1.4 \mathrm{mmol} /$ liter cells). Pump transport and $\mathrm{Na}-\mathrm{K}-\mathrm{Cl}$ cotransport ${ }^{22} \mathrm{Na}$ effluxes were significantly $(P<0.01)$ increased, whereas the rate constant for these effluxes as well as for passive ${ }^{22} \mathrm{Na}$ èflux did not differ from normal. Correction of hypokalemia and maintenance of a normal serum potassium decreased intracellular $\left[\mathrm{Na}^{+}\right]$to $8.2 \pm 1.8 \mathrm{mmol} /$ liter cells, a normal value, and corrected the ouabainsensitive and furosemide-sensitive ${ }^{22} \mathrm{Na}$ effluxes. The results indicate that exposure of erythrocytes to a low potassium environment is responsible for the high intracellular $\left[\mathrm{Na}^{+}\right]$and, in turn, the high sodium efflux in Bartter's syndrome. The normal sodium efflux observed during correction of hypokalemia and the consistently normal rate constants for all three efflux parameters measured suggest that intrinsic sodium transport processes in erythrocytes are normal in Bartter's syndrome.

\section{Introduction}

In 1962, Bartter et al. (1) described two patients with juxtaglomerular hyperplasia, hyperaldosteronism, renal potassium

\footnotetext{
Address reprint requests to Dr. Gill.

Received for publication 25 October 1983 and in revised form 12 July 1984.
}

The Journal of Clinical Investigation, Inc

Volume 74, November 1984, 1724-1729 wasting, and hypokalemic alkalosis, but without hypertension or clinically evident edema or hypovolemia (1). Although Bartter's syndrome has been further characterized, the etiology is still unknown (2). Various renal transport defects have been postulated as proximate causes of Bartter's syndrome and recent work from this laboratory using renal clearance techniques detailed a defect in chloride reabsorption in the loop of Henle in five patients with this syndrome (3). However, no investigator has directly studied renal tubular ion transport in Bartter's syndrome because isolating renal tubule segments from human kidneys is currently impractical and no appropriate animal model for the disease exists.

Erythrocytes are an easily accessible tissue whose membrane contains ion transport systems which may serve as models for epithelial ion pathways (4). Several groups of investigators, postulating that a transport defect in the kidney tubule in Bartter's syndrome may result from a generalized membrane defect, have studied sodium transport in erythrocyte from these patients (5-9). They uniformly found that erythrocytes from patients with Bartter's syndrome contained an elevated intracellular sodium concentration. Furthermore, Cole and O'Regan (8) and Mongeau et al. (9) reported evidence to suggest that an intrinsic membrane defect in the erythrocyte of these patients alters passive sodium transfer sufficiently to cause this net change in steady state sodium content. As chronic hypokalemia from any cause can raise the intracellular sodium concentration of circulating erythrocytes (10), it is important to separate the effects of chronic hypokalemia from those of a putative intrinsic membrane abnormality. To determine whether the defect in ion transport in Bartter's syndrome is present in other tissues or limited to the kidney, we examined intraerythrocyte sodium concentration and sodium efflux in erythrocytes from nine patients with Bartter's syndrome during periods of hypokalemia and eukalemia.

\section{Methods}

Materials. Ouabain was obtained from Aldrich Chemical Co. (Milwaukee, Wisconsin); furosemide was a generous gift from the HoechstRoussel Pharmaceuticals, Inc. (Somerville, NJ); and ${ }^{22} \mathrm{Na}$ was obtained as a chloride salt from New England Nuclear Corp (Boston, MA). All salts were analytic grade.

Patients and control subjects. All nine patients fulfilled the clinical and laboratory criteria for Bartter's syndrome. They presented with 
hypokalemia and manifested hyperreninemia, hyperaldosteronism, normal blood pressure, resistance to the pressor action of intravenous angiotensin, hyperplasia of the juxtaglomerular apparatus, and defective reabsorption of chloride in the loop of Henle. 16 male and 14 female normal volunteers (aged 8 to $54 \mathrm{yr}$ ) comprised the control group which approximated the racial and age characteristics of the patients.

All of the patients discontinued all medications except potassium chloride for at least $2 \mathrm{wk}$ before study. They were hypokalemic when initially studied. Subsequently, their daily intake of $\mathrm{KCl}$ was increased to 20-40 meq every 2-4 $\mathrm{h}$ to achieve and maintain a normal plasma $\mathrm{K}^{+}$(3.3-4.6 meq/liter) for $12 \mathrm{~h}$ or longer before being restudied. Except for oral potassium, all of the patients and controls fasted overnight preceeding the experimental procedure.

Experimental procedure. Venous blood was drawn into heparinized tubes between 8:00 and 10:00 a.m. All the experiments were begun within 30 min after the blood was drawn by centrifuging the sample at $3,000 \mathrm{~g}$ for $5 \mathrm{~min}$. The plasma was aspirated, the buffy coat discarded, and, in some experiments, a small sample of erythrocytes was removed to determine the intracellular sodium concentration. The remaining erythrocytes were washed three times with $30 \mathrm{ml}$ of a solution that contained $148 \mathrm{mM}$ sodium chloride, $5 \mathrm{mM}$ potassium chloride, $200 \mathrm{mg} / 100 \mathrm{ml}$ glucose, and $10.4 \mathrm{mM}$ sodium phosphate, and had a pH of 7.4 at $37^{\circ} \mathrm{C}$ (buffer). The cells were loaded with ${ }^{22} \mathrm{Na}^{+}$by incubating them in a shaking water bath at $37^{\circ} \mathrm{C}$ in buffer (hematocrit $\sim 12 \%$ ) to which ${ }^{22} \mathrm{Na}^{+}$had been added to give a concentration of $\sim 1 \mu \mathrm{Ci} / \mathrm{ml}$. Erythrocytes from eight eukalemic patients and six controls were also incubated in buffer from which $\mathrm{KCl}$ had been omitted in order to raise the intracellular $\mathrm{Na}^{+}$concentration. After a 2-h preincubation, a small aliquot of erythrocytes was removed to determine the intracellular sodium concentration; the remaining cells were washed three times with $3 \mathrm{ml}$ of buffer to remove all extracellular ${ }^{22} \mathrm{Na}^{+}$. The cells were then added to incubation flasks containing prewarmed media which consisted of either buffer alone, buffer with ouabain at a concentration of $10^{-4} \mathrm{M}$, or buffer with ouabain at $10^{-4} \mathrm{M}$ and furosemide at $10^{-3} \mathrm{M}$. It was necessary to add a few drops of $1 \mathrm{~N}$ $\mathrm{NaOH}$ to the flask containing furosemide to readjust the $\mathrm{pH}$ to 7.4. The hematocrit of each incubation flask was $\sim 4 \%$. At the start of the incubation and, thereafter, at timed intervals of $20 \mathrm{~min}$ for $1 \mathrm{~h}$, the suspensions were thoroughly mixed and an aliquot removed, the cells separated from the supernatant, and the radioactivity of the supernatant determined in a Beckman Gamma 9000 Spectrometer (Beckman Instruments, Fullerton, CA). At some time during the course of the incubation, an aliquot of each suspension was removed and mixed with an equal volume of water and one drop of a nonionic detergent (Cutscum; Fisher, Fairlawn, NJ) to hemolyze the erythrocytes for determination of the total counts present in the cell suspension. This measurement represented the radioactivity initially present in the cells.

The rate constant for ${ }^{22} \mathrm{Na}^{+}$efflux $\left({ }^{\circ} k\right)^{1}$ was calculated as described by Priestland and Whittam (11) from the samples taken at 0 and 60 $\min$. The other intervening samples were taken to insure that ${ }^{\circ} k$ was constant over $1 \mathrm{~h}$ for each experiment. $\mathrm{Na}^{+}$efflux $\left({ }^{\circ} \mathrm{M}\right)$ is the product of ${ }^{\circ} \mathrm{k}$ and the post-preincubation $\left[\mathrm{Na}_{\mathrm{i}}{ }^{+}\right]$. Ouabain-sensitive $\mathrm{Na}^{+}$efflux, $E_{\text {ouab }}$, equals ${ }^{\circ} \mathrm{M}-{ }^{\circ} \mathbf{M}^{\text {ouab }}$, and furosemide-sensitive $\mathrm{Na}^{+}$efflux, $\mathrm{E}_{\text {fur }}$, equals ${ }^{\circ} \mathbf{M}^{\text {ouab }}-{ }^{\circ} \mathbf{M}^{\text {fur }}$. The rate constant for ouabain- and furosemideresistant $\mathrm{Na}^{+}$efflux $\left(k_{\mathrm{p}}\right)$ equals ${ }^{\circ} \mathbf{k}^{\text {ouab+fur }}$. Pre- and post-preincubation $\left[\mathrm{Na}_{i}{ }^{+}\right]$were determined, using a modification of the method described

1. Abbreviations used in this paper: ${ }^{\circ} k$, rate constant for ${ }^{22} \mathrm{Na}^{+} ; k_{\mathrm{p}}$, rate constant for ouabain- and furosemide-resistant $\mathrm{Na}^{+}$efflux; ${ }^{\circ} \mathrm{M}$, $\mathrm{Na}^{+}$efflux. by Beilin et al. (12), by centrifuging the samples in special tubes with an internal diameter of their lower half of $5 \mathrm{~mm}$ at $17,000 \mathrm{~g}$ for 5 min. The amount of trapped $\mathrm{Na}^{+}$was estimated to be $4.8 \%$ of the buffer $\mathrm{Na}^{+}$concentration. Several successive determinations of intracellular $\left[\mathrm{Na}^{+}\right]$in one individual comparing this method to one in which the extracellular $\mathrm{Na}^{+}$is reduced to an unmeasurable concentration by washing the cells in an isotonic but nominally $\mathrm{Na}^{+}$-free choline media yielded identical values. Cell $\mathrm{H}_{2} \mathrm{O}$ of the post-preincubation sample was determined by a gravimetric method previously described by Riddick et al. (13).

Statistical analysis. Statistical comparisons were performed using the two-tailed Student's $t$ test.

\section{Results}

Fresh erythrocytes from hypokalemic patients with Bartter's syndrome contained a significantly higher mean intracellular sodium than erythrocytes from a group of normal controls (11.8 \pm 1.8 vs. $7.3 \pm 1.4 \mathrm{mmol} /$ liter cells, $P<0.001)$. During treatment with oral potassium chloride, which increased mean plasma $\mathrm{K}^{+}$from $2.6 \pm 0.2$ to $3.7 \pm 0.2 \mathrm{meq} / \mathrm{liter}$ with a slight but insignificant decrease in mean plasma bicarbonate from $30 \pm 1.2$ to $28 \pm 0.9 \mathrm{meq} / \mathrm{liter}$, mean erythrocyte intracellular sodium decreased to $8.2 \pm 1.8 \mathrm{mmol} /$ liter cells $(n=9)$, a value not significantly different from normal. A decrease in intracellular sodium concentration occurred in every patient so studied with the greatest decrease observed in those patients with the highest plasma potassium (Fig. 1).

When cells from eukalemic patients and controls were incubated in nominally $\mathrm{K}^{+}$-free media, the intraerythrocyte sodium concentration increased by 1.1-1.2 mmol/liter cells per $\mathrm{h}$ in both. Conversely, when cells from hypokalemic patients were incubated in media with a potassium concentra-

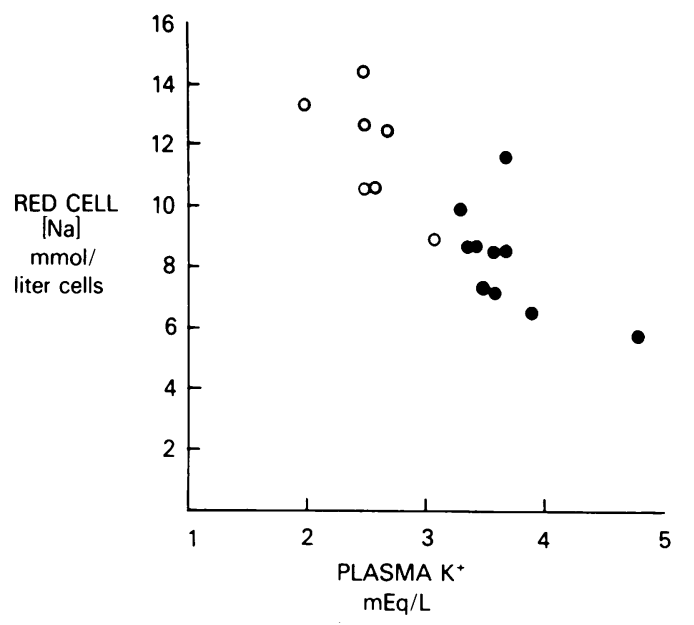

Figure 1. The concentration of $\mathrm{Na}^{+}$in fresh erythrocytes from patients with Bartter's syndrome (Red cell $[\mathrm{Na}]$ ) plotted as a function of plasma $\mathrm{K}^{+}$concentration. The cells were drawn before $(0 ; n=6)$ and after $(\bullet ; n=9)$ intensive treatment with oral $\mathrm{KCl}$. One patient was studied on two different days both before and after treatment. Normal range for plasma $\mathrm{K}^{+}$is $3.3-4.6 \mathrm{meq} / \mathrm{liter}$. 
tion of $5 \mathrm{mM}$, the high intraerythrocyte sodium decreased by $1.1 \mathrm{mmol} /$ liter cells per $\mathrm{h}$.

Ouabain-sensitive sodium efflux varied directly with the intracellular sodium concentration (Fig. 2). The means of this transport parameter for the eukalemic patients and the controls did not differ (Table I). The mean rate constants for ouabainsensitive ${ }^{22} \mathrm{Na}$ efflux did not differ among any of the groups studied (Table II). The mean ouabain-resistant, furosemidesensitive ${ }^{22} \mathrm{Na}$ efflux in Bartter's syndrome was significantly higher in cells which contained a higher than normal intracellular $\mathrm{Na}$, but did not differ from the control population when intracellular Na was normal (Table I). Two patients (J.P. and L.P.) who are brothers had values that remained higher than normal (mean $\pm 2 \mathrm{SD}$ ) during eukalemia. The mean rate constants for ouabain-resistant, furosemide-sensitive ${ }^{22} \mathrm{Na}$ efflux did not differ among any of the groups studied (Table II). Only the cells obtained from J.P. and preincubated in $5 \mathrm{mM}$ $\mathrm{K}^{+}$media manifested a significantly higher than normal value for this parameter $(0.1 / \mathrm{h}$ during hypokalemia and eukalemia).

The rate constant for ouabain- and furosemide-resistant ${ }^{22} \mathrm{Na}$ efflux was also the same for all groups studied (Table I). The patient (J.P.) who had the highest value for furosemidesensitive efflux also had a value for $k_{\mathrm{p}}$ that persistently exceeded the normal range for this parameter (mean $\pm 2 \mathrm{SD}$ ). The reason for these abnormalities in erythrocyte sodium effluxes in J.P. is unknown. Although the mean rate constant for passive sodium efflux did not differ significantly from normal, mean

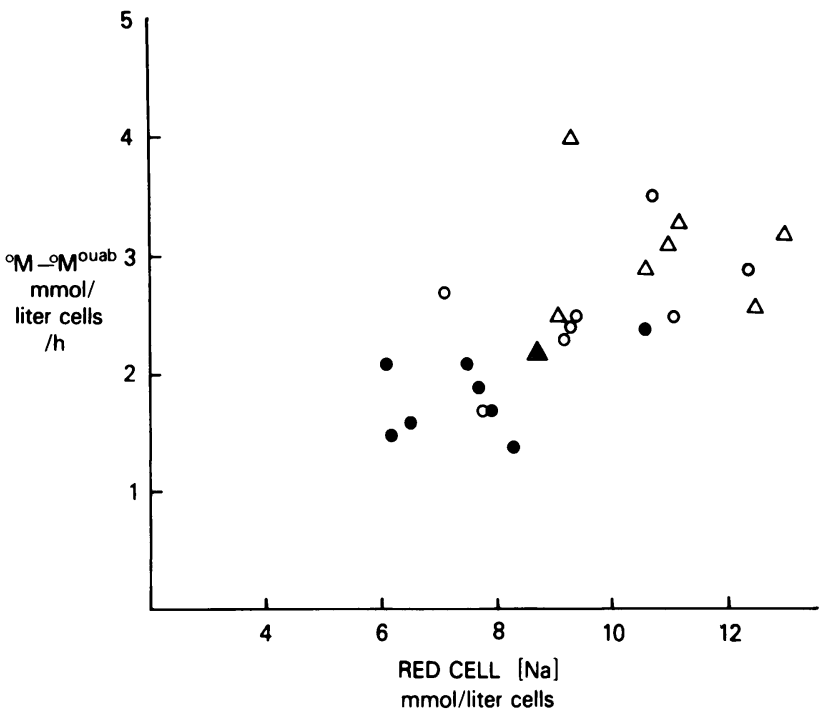

Figure 2. The ouabain-sensitive $\mathrm{Na}^{+}$efflux in erythrocytes from patients with Bartter's syndrome vs. the erythrocyte $\mathrm{Na}^{+}$(Red cell [Na]) concentration. Erythrocytes obtained from the hypokalemic patients were assayed for intracellular $\mathrm{Na}^{+}$and ouabain-sensitive $\mathrm{Na}$ efflux after a 2-h preincubation in buffer (O). Erythrocytes obtained from eukalemic patients were similarly assayed after a 2 -h preincubation in either buffer $(\bullet)$ or buffer from which $\mathrm{K}^{+}$had been omitted $(\Delta)$. passive sodium efflux was significantly higher in the eukalemic patients than in control subjects $(0.71 \pm 0.29$ vs. $0.47 \pm 0.13$ $\mathrm{mmol} /$ liter cells per $\mathrm{h}, P<0.05$ ). This finding results from the insignificant but slightly higher mean $\left[\mathrm{Na}_{i}\right]$ in the eukalemic patients multiplied by the slightly higher $k_{\mathrm{p}}$.

Erythrocyte potassium and water also did not differ among any of the groups studied (data not shown).

\section{Discussion}

Fresh erythrocytes from patients with Bartter's syndrome contained a higher than normal concentration of sodium. After correcting the hypokalemia of all nine patients with oral potassium supplementation and maintaining the eukalemia for $12 \mathrm{~h}$ or longer, the concentration of sodium in their erythrocytes did not significantly differ from the control population. A high intraerythrocyte sodium concentration has previously been demonstrated in patients who were hypokalemic secondary to a variety of causes, and in one of these patients, correction of the hypokalemia resulted in a lowering of the high intracellular sodium (10). Sodium concentration has also been observed to rise when erythrocytes are incubated in vitro in a media with a potassium concentration of $<4.0$ $\mathrm{mM}$ (14). Intracellular sodium and extracellular potassium are actively exchanged in erythrocytes by the sodium-potassium ATPase. The activity of this enzyme is usually assayed in erythrocytes as the ouabain-inhibitable portion of sodium efflux. Kinetic studies plotting pump activity against external potassium show an apparent Michaelis constant $\left(K_{\mathrm{m}}\right)$ for external potassium variously estimated to be 1-3 $\mathrm{mM}$ (15, 16). Thus, a plasma $\left[\mathrm{K}^{+}\right]$in this range which clinically occurs in untreated patients with Bartter's syndrome can profoundly affect the activity of this transport process in erythrocytes and result in a net gain of intracellular sodium. Correction of hypokalemia or in vitro incubation in a high potassium media increases the activation of the erythrocyte sodium-potassium pump and returns intracellular sodium to normal. When an accelerated pump activity was observed in erythrocytes from Bartter's syndrome or from controls, it was in cells with a high intracellular sodium content and it occurred when the cells were exposed to a solution with a more normal potassium concentration.

Human erythrocytes exposed to ouabain can still extrude sodium from their interior against an electrochemical gradient (17). This net outflux requires the presence of sodium, potassium, and chloride on the same side of the membrane (18), follows sigmoid kinetics when sodium efflux is related to internal sodium concentration (19), and is inhibited by furosemide (20). In addition, sodium can be transported from cells exposed to both ouabain and furosemide via an unknown mechanism but which behaves for the most part as a membrane leak (19). Similar mechanisms for the transport of sodium occur in epithelial tissues (21) including the loop of Henle (22), the putative location of the defect which causes Bartter's syndrome (3). 


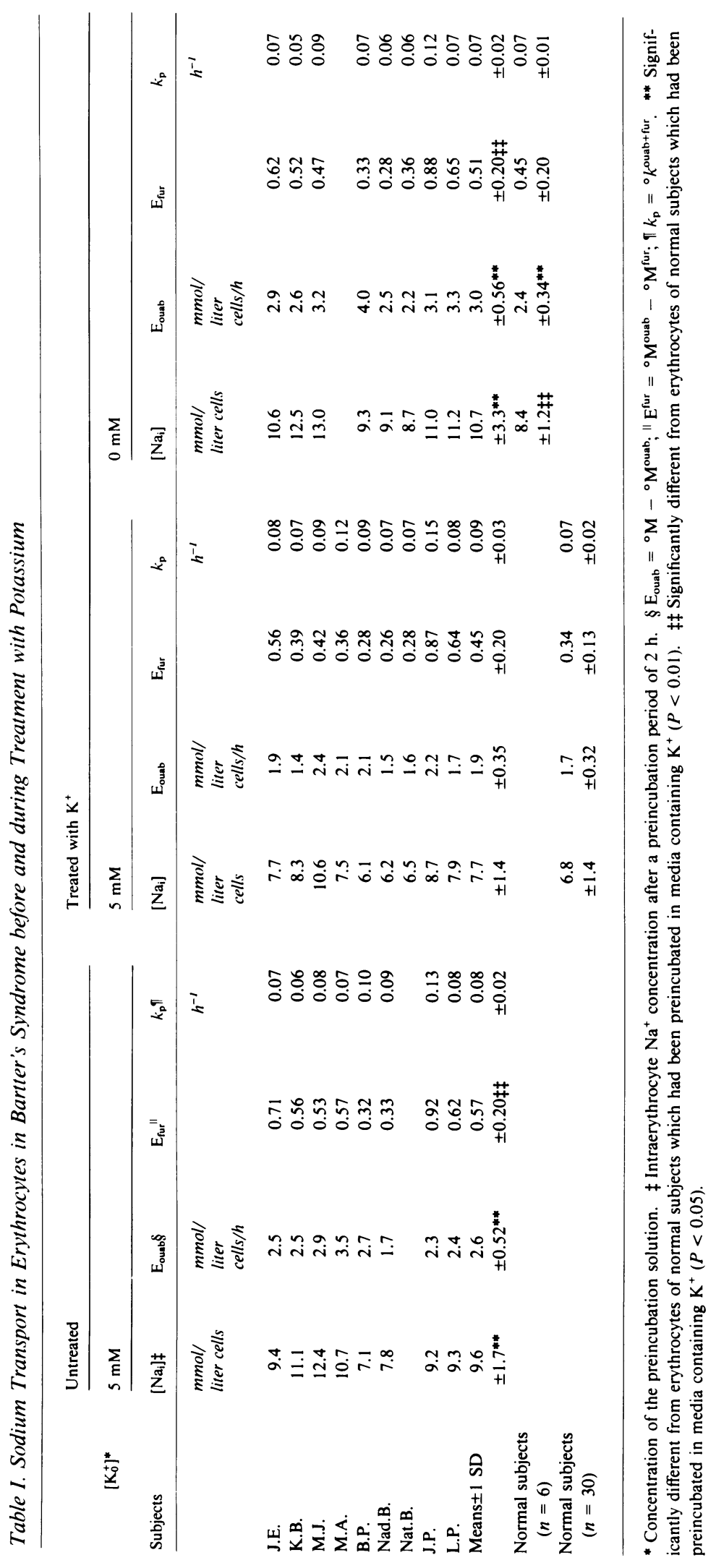

1727 Erythrocyte Sodium Transport in Bartter's Syndrome 
Table II. Ouabain-sensitive and Ouabain-resistant, Furosemide-sensitive ${ }^{22} \mathrm{Na}$ Efflux

Rate Constants $\left(h^{-1}\right)$ in Bartter's Syndrome before and during Treatment with Potassium

\begin{tabular}{|c|c|c|c|c|c|c|}
\hline \multirow{3}{*}{$\begin{array}{l}\left.\qquad \mathrm{K}^{+}\right]^{*} \\
\text { Subjects }\end{array}$} & \multirow{2}{*}{\multicolumn{2}{|c|}{$\begin{array}{l}\text { Untreated } \\
5 \mathrm{mM}\end{array}$}} & \multicolumn{4}{|c|}{ Treated with $\mathrm{K}^{+}$} \\
\hline & & & \multicolumn{2}{|l|}{$5 \mathrm{mM}$} & \multicolumn{2}{|l|}{$0 \mathrm{mM}$} \\
\hline & $k_{0-8 \neq}$ & $k_{\mathrm{f}-\mathrm{s}}$ & $k_{0-s}$ & $k_{\mathrm{f}-\mathrm{s}}$ & $k_{0-s}$ & $k_{\mathrm{f}-\mathrm{s}}$ \\
\hline \multicolumn{7}{|l|}{ Patients } \\
\hline $\begin{array}{l}(n=8) \\
(n=9)\end{array}$ & $0.27 \pm 0.06^{\prime \prime}$ & $0.06 \pm 0.02$ & $0.25 \pm 0.05$ & $0.06 \pm 0.02$ & $0.28 \pm 0.06$ & $0.05 \pm 0.02$ \\
\hline \multicolumn{7}{|l|}{ Controls } \\
\hline $\begin{array}{l}(n=6) \\
(n=30)\end{array}$ & & & $0.25 \pm 0.06$ & $0.05 \pm 0.02$ & $0.29 \pm 0.07$ & $0.05 \pm 0.03$ \\
\hline
\end{tabular}

* Concentration of preincubation solution. $\ddagger k_{0-\mathrm{s}}={ }^{\circ} \mathbf{k}-{ }^{\circ} \mathbf{k}^{\text {ouab }} ; \S k_{\mathrm{f}-\mathrm{s}}={ }^{\circ} \mathbf{k}^{\text {ouab }}-{ }^{\circ} \mathbf{k}^{\text {ouab }+f u r}$. "Mean \pm 1 SD.

Several groups of investigators have used erythrocytes as potential tools with which to investigate these membrane transport processes in patients with Bartter's syndrome (5-9). In 1972, Gardner et al. (5) found that the rate constant for total sodium efflux was lower in 6 out of 8 patients with Bartter's syndrome than in a group of 16 normal subjects. However, subsequent investigators have consistently found the opposite, although only Oliver et al. (6) reported this difference to be statistically significant. The different findings of Gardner et al. (5) may result from an unusually high total sodium efflux rate constant in their control group. Oliver et al. (6) in a study of one family with five affected siblings, five unaffected siblings, and their unaffected parents further fractionated $\mathrm{Na}^{+}$ efflux into pump (ouabain-sensitive) and nonpump (ouabainresistant) rate constants. They reported an increase only in the nonpump fraction in patients with Bartter's syndrome. Gall et al. (7), by characterizing active sodium transport as that inhibited by ouabain plus ethacrynic acid and defining passive $\mathrm{Na}$ leak as the remaining nonsuppressible portion, reported that the rate constants for both active sodium transport and passive leak were elevated in one patient with Bartter's syndrome. Cole and O'Regan (8) confirmed the finding of a high rate constant for passive $\mathrm{Na}^{+}$efflux in a group of five unrelated patients with Bartter's syndrome whom they compared with five matched controls. They also used ethacrynic acid to inhibit cotransport and to measure the residual passive transport. In a recently published study, Mongeau et al. (9) also reported that the rate constant for passive sodium permeability in five children with Bartter's syndrome was significantly greater than in four paired controls. These investigators measured ouabainand furosemide-resistant sodium efflux from sodium-loaded, potassium-depleted erythrocytes into a magnesium chloridesucrose medium.

In the present study, none of the rate constants for ${ }^{22} \mathrm{Na}$ efflux for erythrocytes from patients with Bartter's syndrome differed from the control group. Although one patient (J.P.) consistently manifested a high passive sodium efflux rate constant as well as a high furosemide-sensitive sodium efflux, his brother (L.P.) had rate constants for passive and furosemidesensitive sodium efflux that were within the normal range. Therefore, a defect in erythrocyte sodium permeability in patient J.P. seems unlikely to be a specific feature of Bartter's syndrome in this family. The reason why the values for passive sodium efflux rate constants were supranormal in earlier studies cited above but were normal in the present study is unclear. In the study by Cole and O'Regan (8), two of their five patients manifested rate constants for passive sodium efflux similar to that of our patients, while only one of their patients manifested a value outside the relatively wide normal range we found for a population of 30 normal controls $(0.05-$ $0.14)$. It is difficult to directly compare our results with those of Mongeau et al. (9) because of methodological differences. The values for their five patients ranged from 0.018 to 0.039 , and for their four controls, from 0.011 to 0.019 . The even wider range of values we found in our larger control population suggests that the statistically significant results reported in both of the previously cited studies may have been due to their testing a relatively small number of subjects and controls. Apart from these studies in Bartter's syndrome, the only documented examples of which we are aware of a primary increase in erythrocyte membrane permeability have been in patients with varying degrees of hemolytic anemia (23), which is not a feature of Bartter's syndrome.

None of the studies of erythrocyte sodium flux in Bartter's syndrome have shown an abnormality of the sodium-potassiumchloride cotransport system and we have confirmed this result in the present report. This system is of special interest since it shares many of the properties of the transport system in the thick ascending limb of the loop of Henle (24), the postulated locus of the abnormal renal tubular chloride handling observed in patients with Bartter's syndrome (3). No evidence for such a defect in membrane transport has been found in studies of erythrocyte sodium efflux.

In conclusion, the present studies confirm the finding of an elevated erythrocyte sodium concentration in patients with Bartter's syndrome. This abnormality appears to result from 
the hypokalemic state and not from an intrinsic erythrocyte membrane defect in sodium transport. In addition, the previous finding by others of an abnormality in passive sodium efflux in patients with Bartter's syndrome could not be confirmed.

\section{Acknowledgment}

The authors are greatly indebted to Dr. Floyd M. Kregenow for his generous support and helpful suggestions in the performance of these studies and in the preparation of this manuscript.

\section{References}

1. Bartter, F. C., P. Pronove, J. R. Gill, Jr., and R. C. MacCardle. 1962. Hyperplasia of the juxtaglomerular complex with hyperaldosteronism and hypokalemic alkalosis. Am. J. Med. 33:811-828.

2. Gill, J. R., Jr. 1980. Bartter's syndrome. Ann. Rev. Med. 31:405419.

3. Gill, J. R., Jr., and F. C. Bartter. 1978. Evidence for a prostaglandin-independent defect in chloride reabsorption in the loop of Henle as a proximal cause of Bartter's syndrome. Am. J. Med. 65:766-772.

4. Palfrey, H. C., and P. Greengard. 1981. Hormone-sensitive ion transport systems in erythrocytes as models for epithelial ion pathways. Ann. NY Acad. Sci. 372:291-308.

5. Gardner, J. D., A. P. Simopoulos, A. Lapey, and S. Shibolet. 1972. Altered membrane sodium transport in Bartter's syndrome. $J$. Clin. Invest. 51:1565-1571.

6. Oliver, J. F., V. B. Delaney, and E. Bourke. 1978. Increased erythrocyte sodium permeability in patients with Bartter's syndrome. Miner. Electrolyte Metab. 1:225-230.

7. Gall, G., J. Vaitukaitis, J. E. Haddow, and R. Klein. 1971. Erythrocyte $\mathrm{Na}$ flux in a patient with Bartter's syndrome. J. Clin. Endocrin. Metab. 32:562-567.

8. Cole, C. H., and S. O'Regan. 1981. Effect of treatment with prostaglandin synthetase inhibitors on the erythrocyte sodium transport abnormality of Bartter's syndrome. Pediatr. Res. 15:926-929.

9. Mongeau, J.-G., R. Garay, M. deMendonca, M. Broyer, and P. Meyer. 1983. Erythrocyte $\mathrm{Na}^{+}$and $\mathrm{K}^{+}$transport systems in children with Bartter's syndrome: increase in passive sodium permeability. Kidney Int. 23:530-535.

10. Levin, M. L., F. C. Rector, Jr., and D. W. Seldin. 1972. The effects of chronic hypokalemia, hyponatremia, and acid-base alterations on erythrocyte sodium transport. Clin. Sci. 43:251-263.

11. Priestland, R. N., and R. Whittam. 1968. The influence of external sodium ions on the sodium pump in erythrocytes. Biochem. J. 109:369-374.

12. Beilin, L. J., G. J. Knight, A. D. Munro-Faure, and J. Anderson. 1966. The measurement of sodium concentration in human red blood cells. J. Gen. Physiol. 50:61-74.

13. Riddick, D. H., F. M. Kregenow, and J. Orloff. 1971. The effect of norepinephrine and dibutyryl cyclic adenosine monophosphate on cation transport in duck erythrocytes. J. Gen. Physiol. 57:752-766.

14. Levin, M. L., F. C. Rector, Jr., and D. W. Seldin. 1968. Effects of potassium and oubain on sodium transport in human red blood cells. Am. J. Physiol. 214:1328-1332.

15. Dunham, P. B., and J. F. Hoffman. 1978. Na and K transport in red blood cells. In Physiology of Membrane Disorders. T. E. Andreoli, T. F. Hoffman, and P. D. Fanestil, editors. Plenum Press, NY. 255-272.

16. Garrahan, P. J., and I. M. Glynn. 1967. The sensitivity of the sodium pump to external sodium. J. Physiol. 192:175-188.

17. Hoffman, J. F., and F. M. Kregenow. 1966. The characterization of new energy dependent cation transport processes in red blood cells. Ann. NY Acad. Sci. 137:566-576.

18. Dunham, P. B., G. W. Stewart, and J. C. Ellory. 1980. Chlorideactivated passive potassium transport in human erythrocytes. Proc Natl. Acad. Sci. USA 77:1711-1715.

19. Garay, R., N. Adragna, M. Canessa, and D. Tosteson. 1981. Outward sodium and potassium cotransport in human red blood cells. J. Membrane Biol. 62:169-174.

20. Sachs, J. R. 1971. Oubain-insensitive sodium movements in the human red blood cell. J. Gen. Physiol. 57:259-282.

21. Frizzell, R. A., M. Field, and S. G. Schultz. 1979. Sodium coupled chloride transport by epithelial tissues. Am. J. Physiol. 236(1):F1-8.

22. Burg, M., and L. Stoner. 1976. Renal tubular chloride transport and the mode of action of some diuretics. Annu. Rev. Physiol. 38:3745 .

23. Parker, J. C., and L. R. Berkowitz. 1983. Physiologically instructive genetic variants involving the human red cell membrane. Physiol. Rev. 63:261-313.

24. Ellory, J. C., and G. W. Stewart. 1982. The human erythrocyte $\mathrm{Cl}$-dependent $\mathrm{Na}-\mathrm{K}$ cotransport system as a possible model for studying the action of loop diuretics. Br. J. Pharmacol. 75:183-188. 